\title{
Erlotinib as single agent first line treatment in locally advanced or metastatic activating EGFR mutation-positive lung adenocarcinoma (CEETAC): an open-label, non-randomized, multicenter, phase IV clinical trial
}

Zsolt Markóczy ${ }^{1}$, Veronika Sárosi², Iveta Kudaba³, Gabriella Gálffy ${ }^{4}$, Ülkü Yilmaz Turay ${ }^{5}$, Ahmet Demirkazik Gunta Purkalne" ${ }^{7}$ Attila Somfay ${ }^{8}$, Zsolt Pápai-Székely ${ }^{9}$, Erzsébet Rásó ${ }^{10}$ and Gyula Ostoros ${ }^{1 *}$ (i)

\begin{abstract}
Background: Erlotinib is approved for the first line treatment of epidermal growth factor receptor (EGFR) mutationpositive non-small cell lung cancer. Since the number of prospective studies in Caucasian patients treated in routine clinical setting is limited we conducted a multicenter, phase IV clinical trial to determine the efficacy and safety of erlotinib and to demonstrate the feasibility of the validated standardized companion diagnostic method of EGFR mutation detection.
\end{abstract}

Methods: 651 chemonaive, cytologically or histologically verified advanced stage lung adenocarcinoma patients from Hungary, Turkey and Latvia were screened for exon19 microdeletions and exon21 L858R EGFR mutations using the companion diagnostic EGFR test. EGFR mutation-positive, locally advanced or metastatic lung adenocarcinoma patients received as first line treatment erlotinib at $150 \mathrm{mg} /$ day. The primary endpoint was progression-free survival (PFS).

Results: 62 EGFR mutation-positive patients (9.5\% of screened) were included in the safety/intent-to-treat cohort. Median PFS was 12.8 months (95\%Cl, 9.9-15.8), objective response rate and one-year survival was $66.1 \%$ and $82.5 \%$, respectively. Most frequent treatment related adverse events were diarrhoea and rash. Eastern Oncology Cooperative Group Performance Status (ECOG PS), smoking status and M1a/M1b disease stage were significant prognosticators of PFS ( $p=0.017, p=0.045$ and $p=0.002$, respectively). There was no significant difference in PFS between the subgroups stratified by gender, age or exon19 vs exon21 mutation.

Conclusions: Our study confirmed the efficacy and safety of first line erlotinib monotherapy in Caucasian patients with locally advanced or metastatic lung adenocarcinoma carrying activating EGFR mutations based on the screening with the approved companion diagnostic procedure.

Trial registration: ClinicalTrials.gov Identifier: NCT01609543.

Keywords: Non-small cell lung cancer, Lung adenocarcinoma, EGFR, Erlotinib

\footnotetext{
* Correspondence: ostoros@koranyi.hu

${ }^{1}$ National Koranyi Institute of TB and Pulmonology, Piheno ut 1, Budapest

H-1122, Hungary

Full list of author information is available at the end of the article
} 


\section{Background}

Lung cancer is the leading cause of cancer related mortality worldwide [1]. In European lung adenocarcinoma patients, the incidence of mutations of epidermal growth factor receptor (EGFR) gene is between 5 to $10 \%$ [2-4]. Currently, three EGFR tyrosine kinase inhibitors (EGFRTKIs) including the first-generation, reversible TKI erlotinib and gefitinib as well as the second-generation irreversible TKI afatinib are approved for the treatment of patients with locally advanced or metastatic non-small cell lung cancer (NSCLC) with EGFR activating mutations [5]. For all three agents, the classic mutations of L858R and exon 19 microdeletions can serve as positive predictive biomarkers for response. Of note, a number of additional so called rare EGFR mutations are also sensitizing for EGFR-TKI therapy [4]. Erlotinib was demonstrated to delay symptom progression, improve quality of life and prolong survival as a first-line treatment when compared to standard chemotherapy in patients with exon 19 deletions or exon 21 (L858R) substitution mutations of EGFR [6, 7]. In addition, erlotinib is also approved by the European Medicines Agency for the treatment of patients with locally advanced or metastatic NSCLC after failure of at least one prior chemotherapy regimen (with no mutation analysis requirement) as well as for switch maintenance treatment in patients with locally advanced or metastatic NSCLC with EGFR activating mutations and stable disease after first-line chemotherapy [8].

EGFR mutations are associated with adenocarcinoma histology and more often found in non-smokers. Especially in Asian populations it is also more frequent in females often associates with younger age [9]. These epidemiological characteristics often influence the screening strategy. The presence of KRAS mutations is in general mutually exclusive with EGFR mutations and associates with the lack of response to EGFR-TKIs [10-12].

Our multicenter, phase IV clinical trial was designed to determine the efficacy and safety of erlotinib in routine clinical practice and to demonstrate the feasibility of the validated standardized companion diagnostic method of EGFR mutation detection in Caucasian patients.

\section{Patients and methods}

\section{Patients}

The CEETAC (ClinicalTrials.gov Identifier: NCT01609543) open-label, non-randomized, multicenter trial investigated the efficacy and safety of first line erlotinib monotherapy in routine clinical practice in 10 Hungarian, 5 Turkish and 2 Latvian clinical centers. 651 chemonaive, inoperable, advanced stage lung adenocarcinoma patients were screened for EGFR mutation. Patients above the age of 18 years with histologically or cytologically verified, inoperable, locally advanced, recurrent or metastatic lung adenocarcinoma carrying an activating EGFR mutation (exon 19 microdeletions or exon 21 L858R point mutation) by using Cobas 4800 EGFR Mutation Test at a designated central laboratory were included in the safety as well as in the intent-totreat cohort. 35 Hungarian, 15 Turkish and 12 Latvian patients were eligible to participate in the study. All participants had to have an Eastern Cooperative Oncology Group Performance Status (ECOG PS) between 0 and 2 and a life expectancy of at least 12 weeks. All patients provided written informed consent.

\section{Mutation analysis}

Formalin-fixed paraffin-embedded histological specimens or stained cytological samples were assessed by pathologists at light microscopy and tumour-rich areas were macrodissected in sections and tumor to normal ratio was determined. Cobas ${ }^{\oplus}$ DNA Sample Preparation Kit (Roche Molecular Diagnostics) was then used to isolate DNA according to the manufacturer's instructions. The purity and the concentration of the extracted DNA was determined by Nanodrop 2000 (Thermo Fisher Scientific).

EGFR mutation analysis was carried out by Cobas $^{\oplus}$ EGFR Mutation Test (Roche Molecular Diagnostics), a real-time PCR test for the qualitative detection of mutations for which the safety and efficacy of erlotinib use have been established: exon 19 deletions and exon 21 substitution L858R. The measurement was carried out by $\operatorname{Cobas}^{\otimes}$ z 480 analyzer (Roche Molecular Diagnostics) according to the manufacturer's instructions using the Cobas $^{\oplus} 4800$ System Microwell Plate and the primers, probes and internal controls supplied with the kit.

\section{Treatment and follow-up}

Patients received erlotinib $150 \mathrm{mg} /$ day orally until disease progression, withdrawal of consent or intolerable adverse events. Examination of vital signs and routine hematology was performed at every 28-day visit. Tumor measurement and response grading was performed according to institutional standard of care in line with RECIST version 1.1 and with a maximum interval of 2 months. The primary endpoint was progression-free survival (PFS), secondary endpoints were objective tumor response, one-year survival and safety. PFS was defined from the start of erlotinib treatment to the first documented progression or death. Patients without progression were censored on the date of last evaluable tumor assessment.

\section{Statistical analysis}

The association of gender, disease stage and smoking with the exon19 and exon 21 subgroups was tested with Fisher's exact test. The difference in age and ECOG score in these subgroups was tested by unpaired t-test and by Chi-square test, respectively. PFS was estimated 
with the Kaplan-Meier method and described with the median value and two-sided 95\% confidence interval (CI). Exploratory subgroup analyses of progression-free survival were done with two-sided log-rank test and the ratio of the median survival times including its 95\% confidence intervals are also reported. Multivariate analysis was performed using the Cox-regression model to calculate hazard ratios (HRs) and corresponding confidence intervals. Statistical differences with $p<0.05$ were considered significant.

\section{Results}

\section{Patient characteristics}

Out of the 651 screened patients, 62 with EGFR mutant lung adenocarcinoma were enrolled from 17 participating centers between March 2012 and January 2014 (Fig. 1A). The last study visit was in January 2015 and data collection was closed in June 2015. The clinicopathological characteristics dichotomized by exon 19 and 21 mutations are summarized in Table 1. All but two patients were of Caucasian origin. Mean age at the time of enrollment was 70.5 (range 28 to 86 ) years. There were 50 female and 12 male patients included. 6 patients $(9.7 \%)$ were enrolled with stage IIIb disease. Among the 56 stage IV cases, the most frequently affected sites included 45 (80.4\%) intrapulmonary, 19 (33.9\%) bone and 7 (12.5\%) liver metastasis at the time of enrollment.

\section{Treatment safety}

During the study, 418 adverse events were recorded from 56 patients. $88.2 \%$ of adverse events were grade I
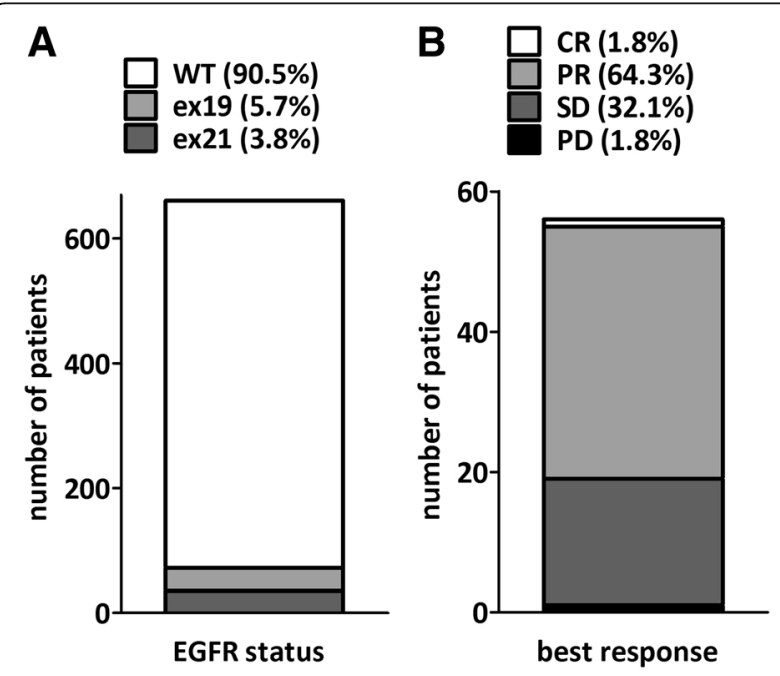

Fig. 1 EGFR mutation status in the screened population and best response to first line erlotinib treatment. (a) Out of the 651 screened patients, 62 carried EGFR mutations including 37 in exon 19 and 35 in exon 21. (b) The distribution of best response among the 56 intent-to-treat patients. (CR - complete remission, PR - partial response, SD - stable disease, $\mathrm{PD}$ - progressive disease) and II. 159 non-serious adverse events (38\%) and 15 serious adverse events (3.6\%) were reported to have causal relationship with erlotinib treatment. The list of nonserious adverse events that occurred at a frequency of $5 \%$ or more is presented in Table 2 . The most frequent adverse events were diarrhoea and rash. Due to adverse events dose modification was applied in fifteen patients (24.1\%) and erlotinib withdrawal was necessary in 5 (8. $1 \%)$ cases.

\section{Treatment efficacy}

Best overall response rate could be established for 56 patients $(90.3 \%$ of the intent-to-treat population). One (1.8\%) complete and $36(64.3 \%)$ partial responses as well as 18 stable $(32.1 \%)$ disease were registered at response evaluation resulting in a disease control rate of $98.2 \%$ (Fig. 1B). Progressive disease (PD) as best tumor response was reported in one patient (1.8\%). 28 patients $(45.2 \%)$ discontinued treatment due to disease progression. 11 disease progression related death occurred during the study. Accordingly, the number of events in the PFS analysis was 40. The median follow-up time was 13.4 months (range 1.3 to 32.9). The progression-free survival was 12.8 months (95\% CI, 9.9-15.8; Fig. 2A).

\section{Exploratory subgroup analysis for progression-free survival}

The progression-free survival in the various subgroups was compared in order to identify the clinicopathological variables that influence treatment outcome (Table 3). There was no significant difference in PFS between the subgroups stratified by gender, age (using the median 70 years of age as cutoff) or mutation exon 19 or 21 . In contrast, ECOG PS was a significant predictor of progression-free survival ( $p=0.017$; Fig. 2D). Never smoker patients also had a significantly increased PFS when compared to ever-smokers (15.4 versus 8.4 months; $p=0.045$; Fig. 2B). Furthermore, M1a disease at the time of screening also associated with increased progressionfree survival when compared to M1b (18.9 versus 8 . 5 months; $p=0.002$; Fig. 2C). Finally, we performed multivariate analyses using a multimodality Coxregression model adjusted for smoking, ECOG and M stage. After multivariate PFS analyses, smoking (HR: 2. 07, CI: $1.04-4.14, p=0.039$ ) and ECOG (HR: 2.21, CI: 1. $21-4.04, p=0.01)$ remained significant factors while $M$ stage (HR: $0.51, \mathrm{CI}: 0.25-1.06, p=0.07$ ) did not reach significance.

\section{Discussion}

In contrast to Asian lung adenocarcinoma patients, there is relatively less information about the first-line EGFR-TKI treatment response rates and progressionfree survival in Caucasian cohorts. Our non-randomized, 
Table 1 Clinicopathological characteristics of the 62 patients dichotomized by exon19 microdeletions and exon21 mutations

\begin{tabular}{|c|c|c|c|c|c|}
\hline & & Total & Exon19 & Exon21 & $p$-value \\
\hline Number of patients & & $62(100 \%)$ & $37(66.1 \%)$ & 25 (33.9\%) & \\
\hline Age (median, range) & & $70.5(28-86)$ & $67(28-81)$ & $71(48-86)$ & 0.088 \\
\hline \multirow[t]{2}{*}{ Gender } & Male & $12(19.4 \%)$ & $8(21.6 \%)$ & $4(16 \%)$ & \multirow[t]{2}{*}{0.747} \\
\hline & Female & $50(80.6 \%)$ & $29(78.4 \%)$ & $21(84 \%)$ & \\
\hline \multirow[t]{3}{*}{ ECOG performance status } & 0 & $24(38.7 \%)$ & $17(46 \%)$ & $7(28 \%)$ & \multirow[t]{3}{*}{0.182} \\
\hline & 1 & $32(51.6 \%)$ & $17(46 \%)$ & $15(60 \%)$ & \\
\hline & 2 & $6(9.7 \%)$ & $3(8 \%)$ & $3(12 \%)$ & \\
\hline \multirow[t]{2}{*}{ Smoking status } & Never-smoker & $42(67.7 \%)$ & $25(67.5 \%)$ & $17(68 \%)$ & \multirow[t]{2}{*}{1.00} \\
\hline & Ever smoker & $20(32.3 \%)$ & $12(32.5 \%)$ & $8(32 \%)$ & \\
\hline \multirow[t]{2}{*}{ Tumor Stage } & $\| l \mid \mathrm{b}$ & $6(9.7 \%)$ & $1(1.6 \%)$ & $5(20 \%)$ & \multirow[t]{2}{*}{0.035} \\
\hline & IV & $56(90.3 \%)$ & $36(98.4 \%)$ & $20(80 \%)$ & \\
\hline
\end{tabular}

Data shown in parentheses are column percentages;

multicenter, phase IV clinical trial including first-line erlotinib treated lung adenocarcinoma patients with activating EGFR mutations was conducted for the very reason. The ORR in our study is in accordance with studies from East-Asia where RRs were found to be 70$75 \%[13,14]$. Interestingly, the LUX-Lung 2 phase II trial of the second-generation covalent TKI inhibitor afatinib demonstrated similar RR in classic EGFR mutant patients [15]. Of note, the 12.8-months median PFS in our cohort is in the range of previously published data (9.4-11.9 months) from other studies $[14,16]$.

Previously, three major randomised, phase III first-line studies have shown a tendency for improved response to erlotinib in patients with exon19 microdeletion-positive

Table 2 Non-serious adverse events during erlotinib treatment

\begin{tabular}{lll}
\hline Adverse event & Number of patients (\%) & Number of events \\
\hline Rash & $36(58.1 \%)$ & 43 \\
Diarrhoea & $17(27.4 \%)$ & 26 \\
Dry skin & $11(17.7 \%)$ & 15 \\
Pruritus & $9(14.5 \%)$ & 10 \\
Asthenia & $5(8.1 \%)$ & 9 \\
Conjunctivitis & $6(9.7 \%)$ & 8 \\
Back pain & $7(11.3 \%)$ & 8 \\
Cough & $8(12.9 \%)$ & 8 \\
Alopecia & $7(11.3 \%)$ & 7 \\
Anaemia & $5(8.1 \%)$ & 6 \\
Growth of eyelashes & $5(8.1 \%)$ & 5 \\
Nausea & $4(6.5 \%)$ & 5 \\
Increased blood AP & $5(8.1 \%)$ & 5 \\
Weight loss & $4(6.5 \%)$ & 5 \\
Headache & $5(8.1 \%)$ & 5 \\
Dyspnoea & $5(8.1 \%)$ & 5 \\
Decreased appetite & $4(6.5 \%)$ & 4 \\
\hline
\end{tabular}

tumors when compared to L858R-positive cases [6, 7, 17]. This tendency has not been observed in the current study, however, the number of patients is limiting the identification of smaller differences in the progression-free survival. Of note, there was no difference at all in the smoking status of patients in the exon 19 and exon 21 mutation subgroup.

While smoking is clearly the most important factor in the development of lung cancer, the prognostic and predicitve significance of smoking status is context dependent. In several studies, never-smokers have improved OS, however, the increased survival is at least in part due to the overall better performance score and the lack of smoking related comorbidities [18-21]. In standard chemotherapy regimens, predictive value of smoking status is limited [19, 22, 23] or only slightly increased survival can be demonstrated in never-smokers when compared to smokers [24, 25]. In contrast, neversmokers seem to have survival benefits in cohorts that include EGFR-TKI treated patients [4]. Owing to the fact that mutation of EGFR gene is more frequent in nonsmokers [26, 27], our study was biased towards neversmokers. Of note, in the ever smoker group there are 4 patients out of 6 are censored beyond one-year that might suggest a decreasing relative risk over time. Nevertheless, there are only 20 patients in the ever smoker subcohort including 3 current smokers. Thus the size of the subcohort prevent us from studying the time-dependent impact of smoking on the progressionfree survival. Nevertheless, we found a significantly improved progression-free survival in never-smokers. One reason might be the smoking induced additional mutational load that can lead to the presence of tumor cell clones with resistance mutations and thus lead to earlier emergence of therapy resistance.

With regards to other clinicopathological parameters, we found no significant difference between the gender- 

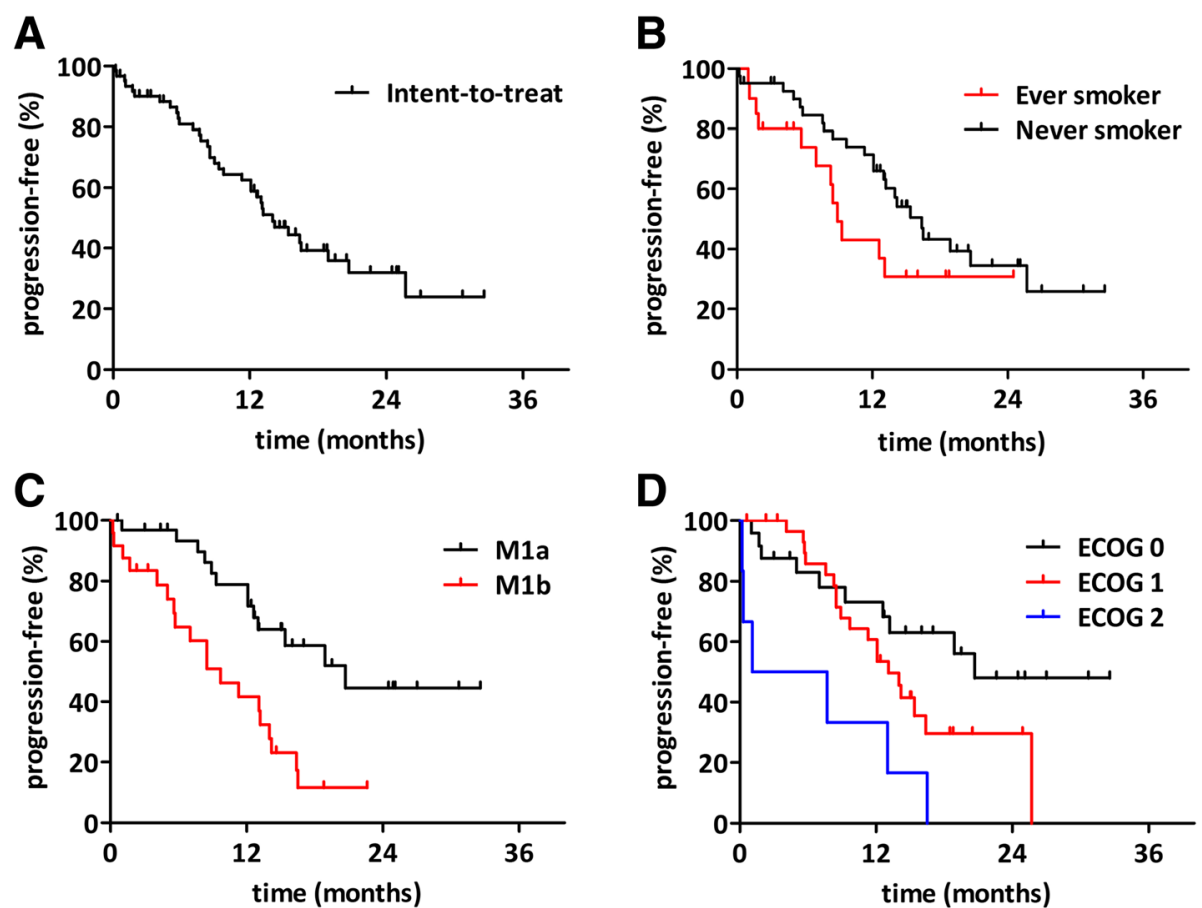

Fig. 2 Kaplan-Meier analysis of progression-free survival. (a) The intent-to-treat cohort had a 12.8 months median PFS. (b) Never smoker patients had increased progression-free survival. (c) Patients with extrathoracic metastasis at the time of screening had lower PFS than patients with pulmonary metastasis. (d) ECOG2 patients demonstrated progression earlier when compared to ECOG1 or ECOG0 performance status

specific PFS. However, the patient population in the present study was biased towards female gender and thus this analysis should be interpreted rather carefully due to the low number $(n=12)$ of male patients in the study.

In the present patient cohort ECOG PS was a significant predictor of PFS. It is in line with a number of other studies where better performance status associated with improved anti-EGFR therapy response $[4,28]$.

Other studies have previously demonstrated that disseminated disease stage have an impact of progessionfree survival in EGFR-TKI treated patients [29]. In the current study, there were only 6 non-metastatic patients included, thus the exploratory analysis of stage as a predictor was limited to M1a and M1b subgroups. Of

Table 3 Exploratory subgroup analysis of progression-free survival $(n=61)$

\begin{tabular}{|c|c|c|c|c|c|c|}
\hline & & $N$ & PFS (months) & Ratio (Cl) & $P$ & $\mathrm{HR}(\mathrm{Cl})$ \\
\hline \multirow[t]{2}{*}{ Gender } & Female & 49 & 13.2 & $1.56(1.101-2.023)$ & 0.447 & $0.719(0.305-1.696)$ \\
\hline & Male & 12 & 8.45 & & & \\
\hline \multirow[t]{2}{*}{ Age } & $\leq 70$ & 31 & 11.7 & $0.76(0.225-1.294)$ & 0.164 & $1.561(0.834-2.922)$ \\
\hline & $>70$ & 30 & 15.4 & & & \\
\hline \multirow[t]{2}{*}{ Smoking } & Never & 41 & 15.4 & $0.545(0.018-1.073)$ & 0.045 & $2.118(1.016-4.418)$ \\
\hline & Ever & 20 & 8.4 & & & \\
\hline \multirow[t]{2}{*}{ Mutation } & Exon 19 & 37 & 13 & $0.79(0.266-1.320)$ & 0.607 & $1.186(0.627-2.243)$ \\
\hline & Exon 21 & 24 & 16.4 & & & \\
\hline \multirow[t]{3}{*}{ ECOG } & 0 & 24 & 18.9 & & 0.017 & \\
\hline & 1 & 31 & 12.6 & & & \\
\hline & 2 & 6 & 4.4 & & & \\
\hline \multirow[t]{2}{*}{ Stage ${ }^{a}$} & M1a & 31 & 18.9 & $2.22(1.708-2.739)$ & 0.002 & $0.334(0.167-0.672)$ \\
\hline & $\mathrm{M} 1 \mathrm{~b}$ & 24 & 8.5 & & & \\
\hline
\end{tabular}


note, patients with metastasis limited to the lung and pleural or pericardial effusion had a signficantly longer PFS when compared to patients with distant organ dissemination.

\section{Conclusion}

Overall, our phase IV clinical trial demonstrated that the companion diagnostic method could identify lung adenocarcinoma patients with activating EGFR mutation with a frequency that was found in other Caucasian patient populations. Furthermore, it has been demostrated that the first-line erlotinib treatment of this patient cohort had an efficacy and safety profile similar to previous large randomized phase III clinical trials.

\section{Abbreviations: \\ Cl: confidence interval; CR: complete remission.; ECOG: PS Eastern Oncology Cooperative Group performance status.; PD: progressive disease.; \\ PFS: Progression-free survival.; PR: partial response.; RR: response rate.; SD: stable disease. \\ Acknowledgements \\ We would like to thank the patients, their families, the nurses and the investigators who were participating in this study.}

\section{Ethical approval}

In Hungary the national level ethic committee approved the study for all particiapting centers (Medical Research Council, Ethics Committee for Clinical Pharmacology, 28,851-0/2011-EKL). In the participating Latvian and Turkish Center local ethic committees approved the studies (Ethics Committee for Clinical Research at Pauls Stradins Clinical University Hospital, No. 180112-14E and the Ethics Committee of the Medical Faculty of the Univeristy of Ankara, B.30.2.ANK.0.20.05.04; 559C 07.03.2012, respectively).

\section{Author contributions}

GO designed the study. ZM, VS, IK, GG, ÜYT, AD, GP, AS, ZP, GO participated as medical investigators in the clinical trial. ER performed molecular analysis. ZM and GO wrote the manuscript. All authors revised the manuscript. All authors read and approved the final manuscript.

\section{Funding}

Funding for the CEETAC study was provided by Hoffmann-La Roche Ltd., Basel, Switzerland.

\section{Availability of data and materials}

The datasets used and/or analysed during the current study are available from the corresponding author on reasonable request.

\section{Consent for publication}

Not applicable.

\section{Competing interests}

The authors declare that they have no competing interests.

\section{Publisher's Note}

Springer Nature remains neutral with regard to jurisdictional claims in published maps and institutional affiliations.

\footnotetext{
Author details

${ }^{1}$ National Koranyi Institute of TB and Pulmonology, Piheno ut 1, Budapest $\mathrm{H}-1122$, Hungary. ${ }^{2}$ Division of Pulmonology, University of Pecs, Pecs, Hungary. ${ }^{3}$ Riga East University Hospital Oncology Center, Riga, Latvia. ${ }^{4}$ Department of Pulmonology, Semmelweis University, Budapest, Hungary. ${ }^{5}$ Clinic of Chest Diseases, Ataturk Chest Diseases and Chest Surgery Training and Research Hospital, Ankara, Turkey. ${ }^{6}$ Department of Medical Oncology, Ibn-i Sina Hospital, Ankara University Medical Faculty, Ankara, Turkey.
}

${ }^{7}$ Oncology Institute, Riga Stradins University, Riga, Latvia. ${ }^{8}$ Department of Pulmonology, University of Szeged, Szeged, Hungary. ${ }^{9}$ St. George Hospital of Fejer County, Szekesfehervar, Hungary. ${ }^{10}$ 2nd Department of Pathology, Semmelweis University, Budapest, Hungary.

Received: 2 August 2017 Accepted: 21 March 2018

Published online: 25 May 2018

\section{References}

1. Siegel R, Ma J, Zou Z, Jemal A. Cancer statistics, 2014. CA Cancer J Clin. 2014;64(1):9-29.

2. Boch C, Kollmeier J, Roth A, Stephan-Falkenau S, Misch D, Gruning W, Bauer $\pi$, Mairinger T. The frequency of EGFR and KRAS mutations in non-small cell lung cancer (NSCLC): routine screening data for Central Europe from a cohort study. BMJ Open. 2013;3(4)

3. Kerner GS, Schuuring E, Sietsma J, Hiltermann TJ, Pieterman RM, de Leede GP, van Putten JW, Liesker J, Renkema TE, van Hengel P, et al. Common and rare EGFR and KRAS mutations in a Dutch non-small-cell lung cancer population and their clinical outcome. PLoS One. 2013;8(7):e70346.

4. Lohinai Z, Hoda MA, Fabian K, Ostoros G, Raso E, Barbai T, Timar J, Kovalszky I, Cserepes M, Rozsas A, et al. Distinct epidemiology and clinical consequence of classic versus rare EGFR mutations in lung adenocarcinoma. Journal of thoracic oncology : official publication of the International Association for the Study of Lung Cancer. 2015;10(5):738-46.

5. Reguart N, Remon J. Common EGFR-mutated subgroups (Del19/L858R) in advanced non-small-cell lung cancer: chasing better outcomes with tyrosine kinase inhibitors. Future Oncol. 2015;11(8):1245-57.

6. Zhou C, Wu YL, Chen G, Feng J, Liu XQ, Wang C, Zhang S, Wang J, Zhou S, Ren $\mathrm{S}$, et al. Erlotinib versus chemotherapy as first-line treatment for patients with advanced EGFR mutation-positive non-small-cell lung cancer (OPTIMAL, CTONG-0802): a multicentre, open-label, randomised, phase 3 study. Lancet Oncol. 2011;12(8):735-42.

7. Rosell R, Carcereny E, Gervais R, Vergnenegre A, Massuti B, Felip E, Palmero R, Garcia-Gomez R, Pallares C, Sanchez JM, et al. Erlotinib versus standard chemotherapy as first-line treatment for European patients with advanced EGFR mutation-positive non-small-cell lung cancer (EURTAC): a multicentre, open-label, randomised phase 3 trial. Lancet Oncol. 2012;13(3):239-46.

8. Massarelli E, Johnson FM, Erickson HS, Wistuba II, Papadimitrakopoulou V: Uncommon epidermal growth factor receptor mutations in non-small cell lung cancer and their mechanisms of EGFR tyrosine kinase inhibitors sensitivity and resistance. Lung Cancer 2013, 80(3):235-241.

9. Mitsudomi T, Kosaka T, Yatabe Y. Biological and clinical implications of EGFR mutations in lung cancer. Int J Clin Oncol. 2006;11(3):190-8.

10. Linardou H, Dahabreh IJ, Kanaloupiti D, Siannis F, Bafaloukos D, Kosmidis P, Papadimitriou CA, Murray S. Assessment of somatic k-RAS mutations as a mechanism associated with resistance to EGFR-targeted agents: a systematic review and meta-analysis of studies in advanced non-small-cell lung cancer and metastatic colorectal cancer. Lancet Oncol. 2008;9(10):962-72.

11. Pao W, Wang TY, Riely GJ, Miller VA, Pan Q, Ladanyi M, Zakowski MF, Heelan RT, Kris MG, Varmus HE. KRAS mutations and primary resistance of lung adenocarcinomas to gefitinib or erlotinib. PLoS Med. 2005;2(1):e17.

12. Govindan R, Kratzke RA, Herndon JE, 2nd, Niehans GA, Vollmer R, Watson D, Green MR, Kindler HL, Cancer, Leukemia Group B: Gefitinib in patients with malignant mesothelioma: a phase II study by the Cancer and leukemia group B. Clin Cancer Res 2005, 11(6):2300-2304.

13. Wu JY, Yu CJ, Chang YC, Yang CH, Shih JY, Yang PC. Effectiveness of tyrosine kinase inhibitors on "uncommon" epidermal growth factor receptor mutations of unknown clinical significance in non-small cell lung cancer. Clin Cancer Res. 2011;17(11):3812-21.

14. Keam B, Kim DW, Park JH, Lee JO, Kim TM, Lee SH, Chung DH, Heo DS. Rare and complex mutations of epidermal growth factor receptor, and efficacy of tyrosine kinase inhibitor in patients with non-small cell lung cancer. Int J Clin Oncol. 2014;19(4):594-600.

15. Yang JC, Shih JY, Su WC, Hsia TC, Tsai CM, Ou SH, Yu CJ, Chang GC, Ho CL, Sequist LV, et al. Afatinib for patients with lung adenocarcinoma and epidermal growth factor receptor mutations (LUX-lung 2): a phase 2 trial. Lancet Oncol. 2012;13(5):539-48.

16. Douillard JY, Ostoros G, Cobo M, Ciuleanu T, McCormack R, Webster A, Milenkova T. First-line gefitinib in Caucasian EGFR mutation-positive 
NSCLC patients: a phase-IV, open-label, single-arm study. Br J Cancer. 2014;110(1):55-62.

17. Wu YL, Zhou C, Liam CK, Wu G, Liu X, Zhong Z, Lu S, Cheng Y, Han B, Chen $L$, et al. First-line erlotinib versus gemcitabine/cisplatin in patients with advanced EGFR mutation-positive non-small-cell lung cancer: analyses from the phase III, randomized, open-label, ENSURE study. Annals of oncology : official journal of the European Society for Medical Oncology / ESMO. 2015; 26(9):1883-9.

18. Torok S, Hegedus B, Laszlo V, Hoda MA, Ghanim B, Berger W, Klepetko W, Dome B, Ostoros G. Lung cancer in never smokers. Future Oncol. 2011;7(10): 1195-211.

19. Toh CK, Wong EH, Lim WT, Leong SS, Fong KW, Wee J, Tan EH. The impact of smoking status on the behavior and survival outcome of patients with advanced non-small cell lung cancer: a retrospective analysis. Chest. 2004; 126(6):1750-6.

20. Tammemagi CM, Neslund-Dudas C, Simoff M, Kvale P. Smoking and lung cancer survival: the role of comorbidity and treatment. Chest. 2004;125(1):27-37.

21. Nordquist LT, Simon GR, Cantor A, Alberts WM, Bepler G. Improved survival in never-smokers vs current smokers with primary adenocarcinoma of the lung. Chest. 2004;126(2):347-51.

22. Herbst RS, Prager D, Hermann R, Fehrenbacher L, Johnson BE, Sandler A, Kris MG, Tran HT, Klein P, Li X, et al. TRIBUTE: a phase III trial of erlotinib hydrochloride (OSI-774) combined with carboplatin and paclitaxel chemotherapy in advanced non-small-cell lung cancer. J Clin Oncol. 2005; 23(25):5892-9.

23. Cserepes M, Ostoros G, Lohinai Z, Raso E, Barbai T, Timar J, Rozsas A, Moldvay J, Kovalszky I, Fabian K, et al. Subtype-specific KRAS mutations in advanced lung adenocarcinoma: a retrospective study of patients treated with platinum-based chemotherapy. Eur J Cancer. 2014;50(10):1819-28.

24. Tsao AS, Liu D, Lee JJ, Spitz M, Hong WK. Smoking affects treatment outcome in patients with advanced nonsmall cell lung cancer. Cancer. 2006;106(11):2428-36.

25. Scagliotti GV, Parikh P, von Pawel J, Biesma B, Vansteenkiste J, Manegold C, Serwatowski P, Gatzemeier U, Digumarti R, Zukin M, et al. Phase III study comparing cisplatin plus gemcitabine with cisplatin plus pemetrexed in chemotherapy-naive patients with advanced-stage non-small-cell lung cancer. J Clin Oncol. 2008;26(21):3543-51.

26. Ahrendt SA, Decker PA, Alawi EA, Zhu Yr YR, Sanchez-Cespedes M, Yang SC Haasler GB, Kajdacsy-Balla A, Demeure MJ, Sidransky D. Cigarette smoking is strongly associated with mutation of the K-ras gene in patients with primary adenocarcinoma of the lung. Cancer. 2001;92(6):1525-30.

27. Pham D, Kris MG, Riely GJ, Sarkaria IS, McDonough T, Chuai S, Venkatraman ES, Miller VA, Ladanyi M, Pao W, et al. Use of cigarettesmoking history to estimate the likelihood of mutations in epidermal growth factor receptor gene exons 19 and 21 in lung adenocarcinomas. J Clin Oncol. 2006;24(11):1700-4.

28. Perez-Soler R, Chachoua A, Hammond LA, Rowinsky EK, Huberman M, Karp D, Rigas J, Clark GM, Santabarbara P, Bonomi P. Determinants of tumor response and survival with erlotinib in patients with non-small-cell lung cancer. J Clin Oncol. 2004;22(16):3238-47.

29. Choi CM, Kim MY, Lee JC, Kim HJ. Advanced lung adenocarcinoma harboring a mutation of the epidermal growth factor receptor: $C T$ findings after tyrosine kinase inhibitor therapy. Radiology. 2014;270(2):574-82.

\section{Submit your next manuscript to BioMed Central and we will help you at every step:}

- We accept pre-submission inquiries

- Our selector tool helps you to find the most relevant journal

- We provide round the clock customer support

- Convenient online submission

- Thorough peer review

- Inclusion in PubMed and all major indexing services

- Maximum visibility for your research

Submit your manuscript at www.biomedcentral.com/submit

Biomed Central 